\title{
ROLE OF HYSTEROSCOPY IN EVALUATION OF INTRAUTERINE PATHOLOGY
}

Veresnyuk N1, Pyrohova V1, Malachynska $\mathrm{M}^{2}$

${ }^{1}$ Department of Obstetrics, Gynecology and Perinatology, Danylo Halytsky Lviv National Medical University, Lviv, Ukraine

${ }^{2}$ Lviv Regional Peproductive Health Center, Lviv, Ukraine

\section{OBJECTIVES}

Hysteroscopy is the gold standard for evaluation of uterine cavity. It can be performed either as office setting or as day care procedure under general anaesthesia. The aim of this study was to evaluate the role of hysteroscopy in diagnosis intrauterine causes (adhesions, polyps, endometritis, congenital uterine anomalies, fibroids etc.) of female infertility.

\section{METHODS}

The study was conducted on 134 infertility patients from January 2016 to January 2017. Preoperative diagnosis of intrauterine pathology was established by ultrasonography, hysterosalpingography, magnetic resonance imaging. In all cases we performed hysteroscopy in the follicular phase of the menstrual cycle then we analyzed the results of evaluation.

\section{RESULTS}

We investigated patients between 22 and 44 years old. The mean age of women was $31.6 \pm 6.1$ years. $46(34.3 \%)$ women consulted for primary infertility and $88(65.7 \%)$ had secondary infertility. The mean duration of infertility was $5.2 \pm 3.6$ years. There was no intraoperative or postoperative complication. In $32(23.9 \%)$ cases the hysteroscopic view and anatomopathological examination was normal. In other $102(76.1 \%)$ cases by hysteroscopy was diagnosed different intrauterine pathology as follow: polyps - $56(41.8 \%)$ cases, congenital uterine anomalies - 19 (14.2\%) cases, fibroids - 14 (10.5\%), adhesions - 8 (6.0\%).

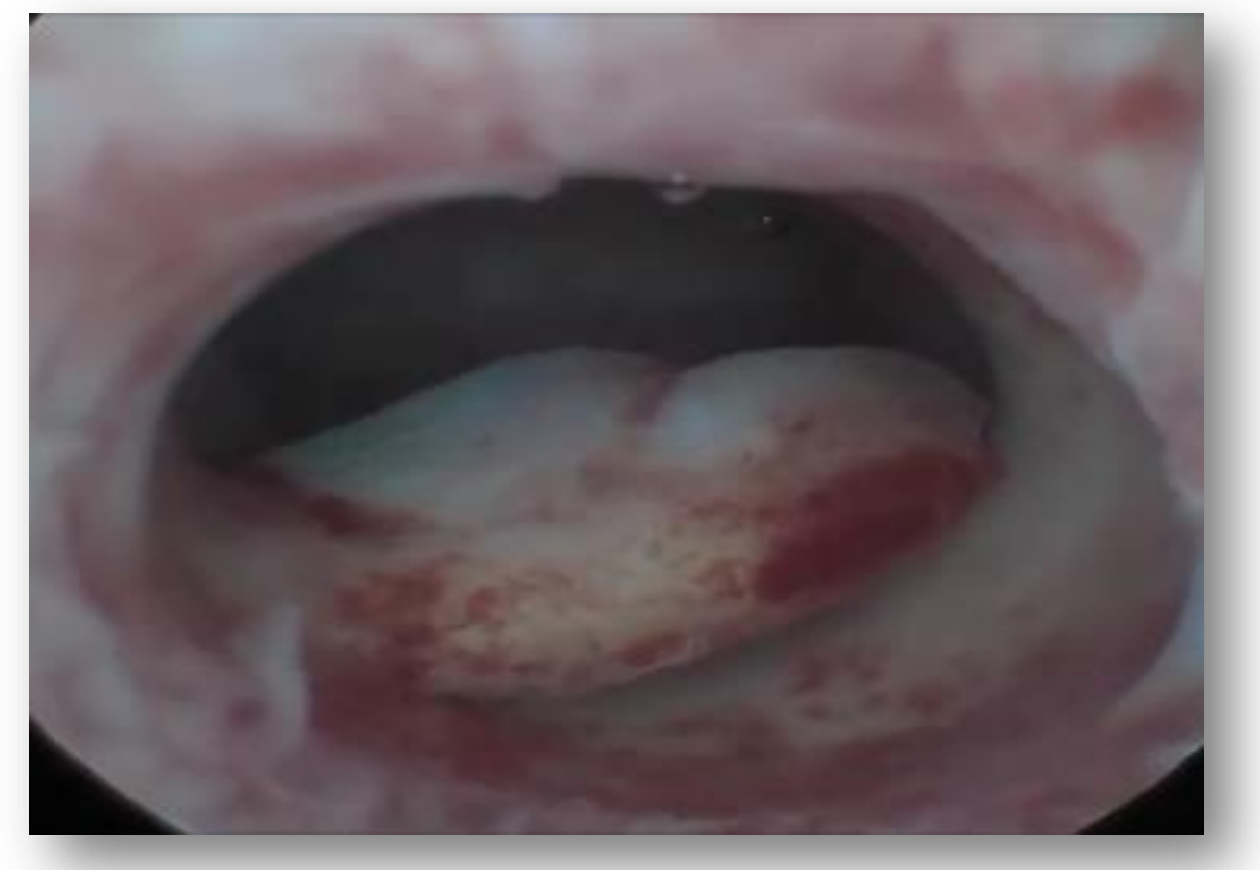

Figure 1. Hysteroscopy of polyp

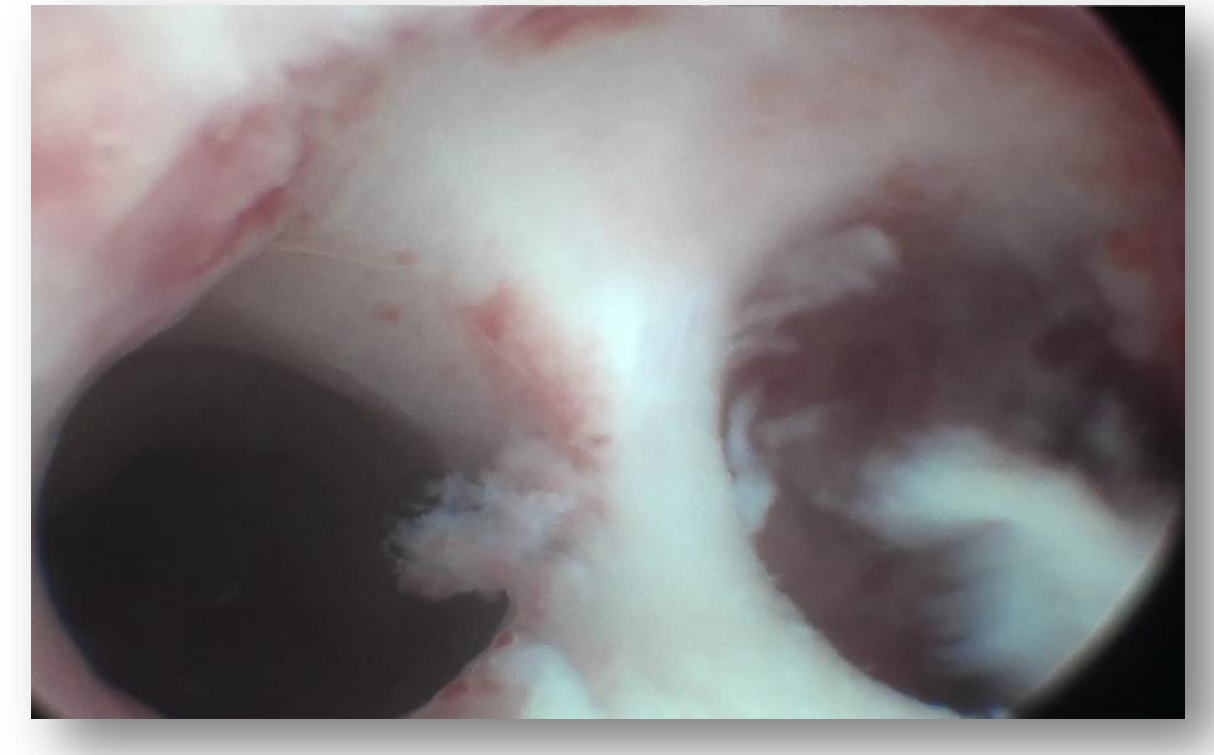

Figure 2. Hysteroscopy of uterine septum

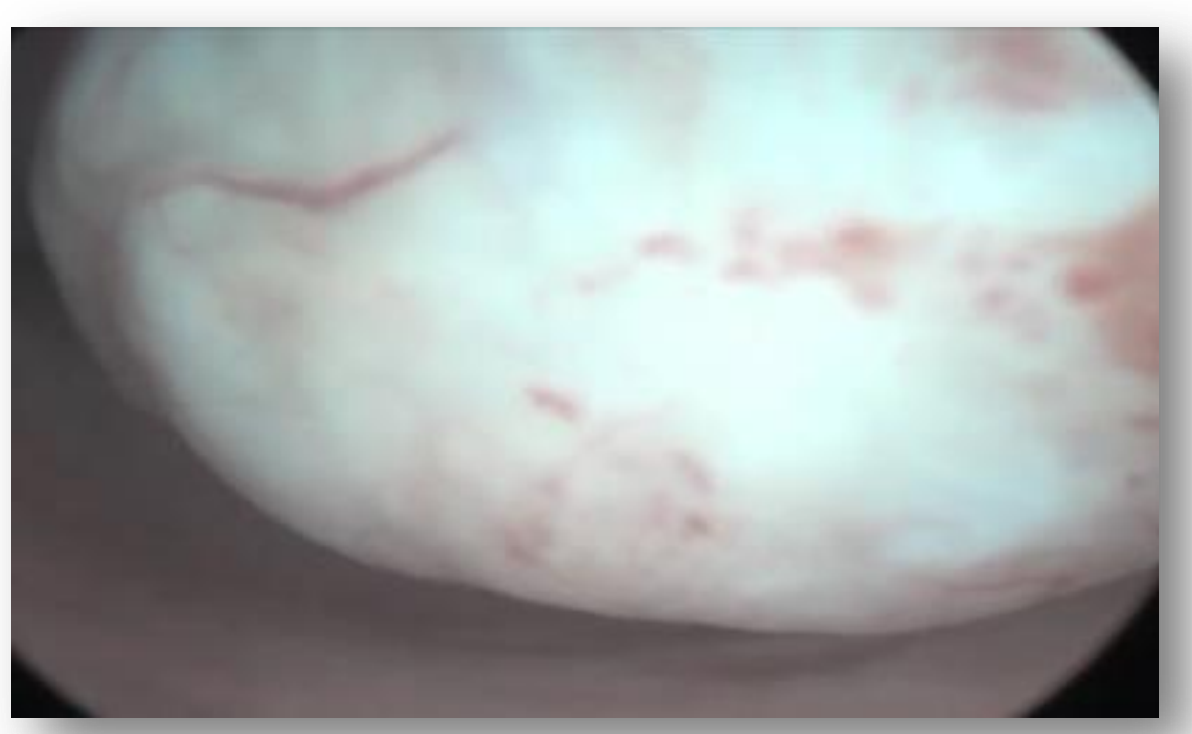

Figure 3. Hysteroscopy of uterine fibroid

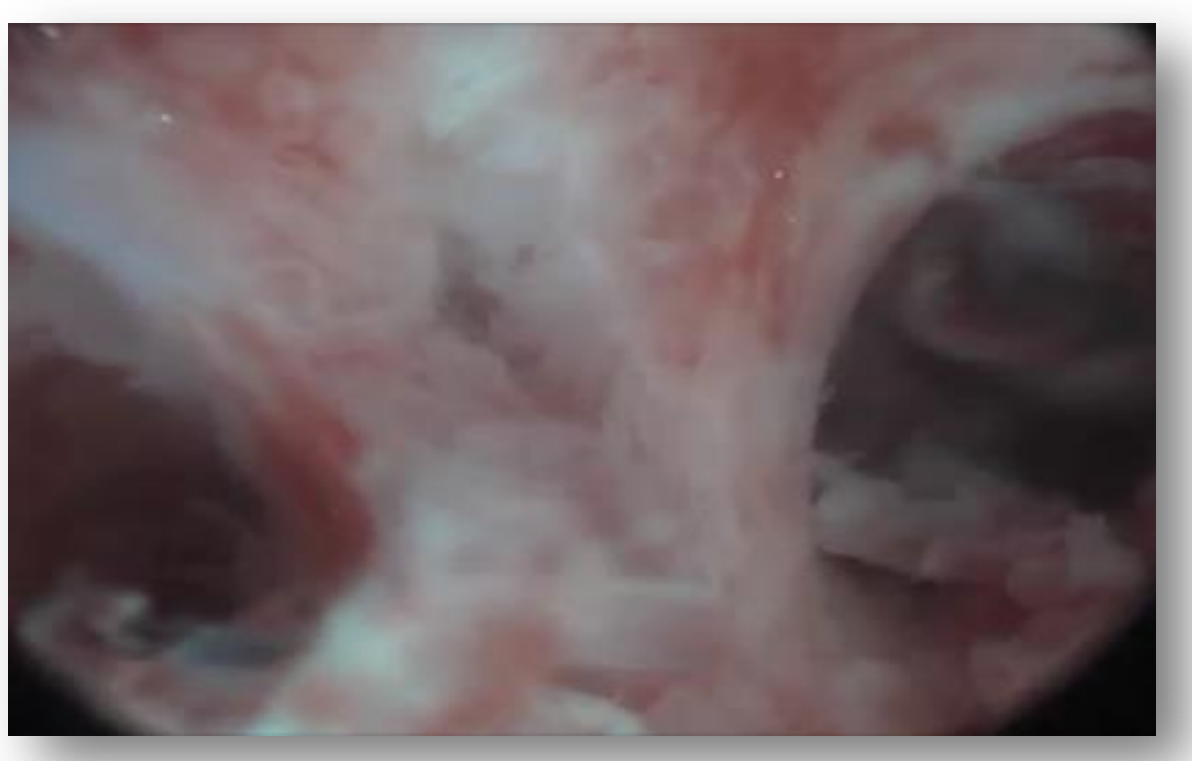

Figure 4. Intrauterine adhesions

In $7(5.2 \%)$ women was diagnosed endometritis certified by anatomopathological examination and in $7(5.2 \%)$ patients was discrepancy with menstrual cycle phase. In $23(17.2 \%)$ cases more than one find in the same patient was diagnosed.

\section{CONCLUSIONS}

Hysteroscopy is a safe and an effective method in diagnostic and treatment of intrauterine pathology in infertility women. Needless to say, that hysteroscopy can identify diseases that aren't diagnosed by ultrasound and hysterosalpingography.

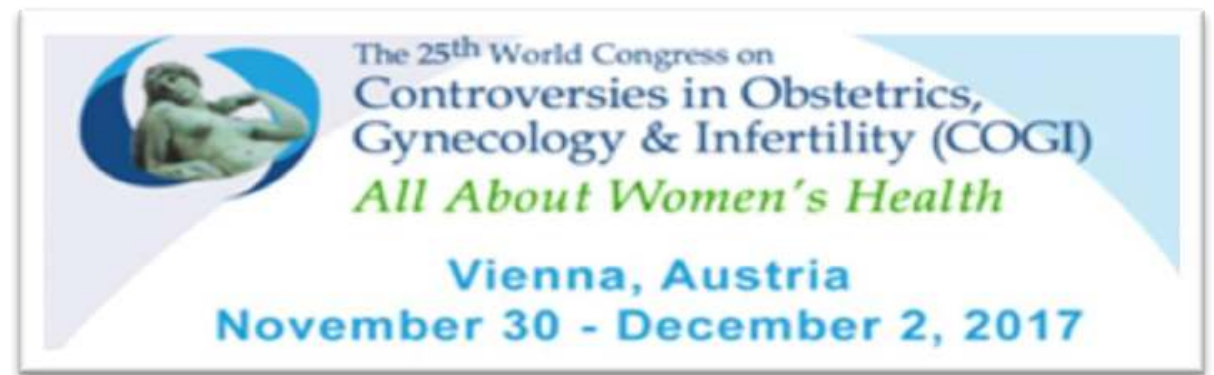

